\title{
MyoD is required for myogenic stem cell function in adult skeletal muscle
}

\author{
Lynn A. Megeney, ${ }^{1}$ Boris Kablar, ${ }^{1}$ Kerryn Garrett, ${ }^{2}$ Judy E. Anderson, ${ }^{2}$ and Michael A. Rudnicki ${ }^{1,3}$ \\ ${ }^{1}$ Institute for Molecular Biology and Biotechnology, Cancer Research Group, McMaster University, Hamilton, Ontario, \\ Canada; ${ }^{2}$ Department of Anatomy, University of Manitoba, Winnipeg, Manitoba, Canada
}

\begin{abstract}
To investigate the function of MyoD in adult skeletal muscle, we interbred MyoD mutant mice with mdx mice, a model for Duchenne and Becker muscular dystrophy. Mice lacking both MyoD and dystrophin displayed a marked increase in severity of myopathy leading to premature death, suggesting a role for MyoD in muscle regeneration. Examination of $M y o D$ mutant muscle revealed elevated numbers of myogenic cells; however, myoblasts derived from these cells displayed normal differentiation potential in vitro. Following injury, MyoD mutant muscle was severely deficient in regenerative ability, and we observed a striking reduction in the in vivo proliferation of myogenic cells during regeneration. Therefore, we propose that the failure of $M y o D$-deficient muscle to regenerate efficiently is not caused by a reduction in numbers of satellite cells, the stem cells of adult skeletal muscle, but results from an increased propensity for stem-cell self-renewal rather than progression through the myogenic program.
\end{abstract}

[Key Words: MyoD; satellite cell; regeneration; Mdx; muscular dystrophy]

Received February 27, 1996; revised version accepted April 8, 1996.

The myogenic regulatory factors (MRFs) form a group of basic helix-loop-helix (bHLH) transcription factors consisting of MyoD, myogenin, Myf-5, and MRF4. The MRFs are expressed exclusively in skeletal muscle, and forcing their expression in a wide range of cultured cells induces the skeletal muscle differentiation program. Therefore, these transcription factors were postulated to have a master regulatory role in the development of the skeletal muscle lineage (for review, see Weintraub et al. 1991).

Gene targeting has clearly elucidated the roles of the MRFs during embryogenesis. The introduction of null mutations in Myf-5, MyoD, myogenin, and MRF4 into the germ line of mice has revealed the hierarchical relationships existing among the MRFs and established that functional redundancy is a feature of the MRF regulatory network (for review, see Rudnicki and Jaenisch 1995; Megeney and Rudnicki 1995). The MRF family can be divided into two functional groups: The primary MRFs, MyoD and Myf-5, are required for the determination of skeletal myoblasts; and the secondary MRFs, myogenin and MRF4, act later in the program, likely as differentiation factors.

Mice lacking a functional $M y o D$ gene were found to have no overt abnormalities in skeletal muscle but expressed about four-fold higher levels of Myf-5 (Rudnicki et al. 1992). Similarly, newborn Myf-5-deficient animals display apparently normal skeletal muscle but die perinatally because of severe rib abnormalities (Braun et al.

\footnotetext{
${ }^{3}$ Corresponding author.
}

1992, 1994). Newborn mice deficient for both $M y o D$ and Myf-5 are totally devoid of skeletal myoblasts and muscle (Rudnicki et al. 1993). Mice lacking myogenin die at birth because of a virtual absence of myofibers; however, normal numbers of MyoD-expressing myoblasts are present (Hasty et al. 1993; Nabeshima et al. 1993; Venuti et al. 1995). In contrast, mice lacking MRF4 are viable with seemingly normal skeletal muscle but display a four-fold increase in myogenin (Patapoutian et al. 1995; Zhang et al. 1995).

Vertebrate skeletal muscle is derived from cells in the prechordal and somitic mesoderm that give rise to committed myogenic cells, which become the skeletal muscle of the head, trunk, and limbs (for review, see Buckingham 1992; Miller 1992; Hauschka 1994). The different myofiber and myogenic constituents of muscle have been postulated to be formed from different lineages of myogenic cells (Miller 1992; Bischoff 1994). In the mouse, primary myofibers develop first at 8.5 days of gestation, followed by secondary myofibers around day 14. Satellite cells, the stem cells of adult skeletal muscle, arise around day 17 of development as a unique myogenic cell lineage (Bischoff 1994).

Satellite cells lie beneath the basal lamina of adult skeletal muscle closely juxtaposed to the myofiber sarcolemma. Satellite cells make up $2 \%-7 \%$ of the nuclei associated with a particular fiber, and the proportion varies with age and muscle group. These adult muscle stem cells are normally mitotically quiescent but are activated (i.e., enter the cell cycle) in response to stress induced by weight-bearing or other trauma, such as injury. 
The descendants of the activated satellite cells, called myogenic precursor cells (mpc), undergo multiple rounds of division before fusing to existing myofibers or forming new myofibers, leading to repair and/or hypertrophy of the damaged or stressed muscle fibers, respectively. Satellite cells form a stable population, suggesting that selfrenewal in the stem-cell compartment maintains the pool of quiescent satellite cells. Moreover, satellite cells and their descendants have a very large potential for proliferation, perhaps as much as 80 doublings, as revealed by experiments in which muscle was subjected to repetitive cycles of injury-induced regeneration (for review, see Grounds and Yablonka-Reuveni 1993; Bischoff 1994).

The expression pattern of MRFs following satellitecell activation and during mpc proliferation and differentiation appears to be distinct from the program manifested during the embryonic development of skeletal muscle. Quiescent satellite cells express no detectable MRFs. Upon activation and entrance into the cell cycle, MyoD is rapidly up-regulated concomitant with expression of proliferating cell nuclear antigen (PCNA), a marker for cell proliferation (e.g., Bravo et al. 1987). Myf-5 and MRF4 are expressed at intermediate times when PCNA and MyoD expression are declining. Myogenin is expressed last during the time associated with fusion and differentiation (Smith et al. 1994; YablonkaReuveni and Rivera 1994). This expression of MyoD early after activation is suggestive of an important role for MyoD in satellite cell function.

The viability and apparently normal skeletal muscle of MyoD mutant mice (Rudnicki et al. 1992), and the early expression of $M y o D$ following satellite cell activation (Smith et al. 1994; Yablonka-Reuveni and Rivera 1994), lead us to consider the hypothesis that MyoD may have some role in the postnatal growth and regeneration of skeletal muscle. To investigate the function of $\mathrm{MyoD}$ in adult skeletal muscle, we interbred $M y o D$ mutant mice with $m d x$ mice carrying a loss-of-function mutation in the dystrophin gene, and performed injury-induced regeneration experiments on muscle in MyoD-deficient animals. Our data clearly establish a role for MyoD in adult muscle and reveal novel insights into the genetic regulation of muscle stem-cell function.

\section{Results}

Mice lacking MyoD and dystrophin exhibit increased myopathy

To determine whether MyoD might have a role in skeletal muscle regeneration, we interbred MyoD-deficient mice (Rudnicki et al. 1992) with the $m d x$ mouse strain as an in vivo bioassay for skeletal muscle regeneration. The $m d x$ mice carry a loss-of-function point mutation in the $\mathrm{X}$-linked dystrophin gene and are therefore an animal model for human Duchenne and Becker muscular dystrophy (Sicinski et al. 1989; Ahn and Kunkel 1993). The $\mathrm{mdx}$ mice display extensive necrosis of muscle fibers by
2 weeks of age, but unlike humans, maintain skeletal muscle integrity due to a high muscle regenerative capacity. This regeneration results in the formation of additional muscle fibers, which leads to a significant level of muscle hypertrophy. Hypertrophy in $m d x$ muscle is characterized by a $25 \%$ increase in the number of fibers, a four-fold increase in the distribution of the fiber calibers, centrally located nuclei within $70 \%-80 \%$ of all fibers, and a 1.7-fold increase in muscle mass (Anderson et al. 1987; Carnwath and Shotton 1987; Coulton et al. 1988; e.g., see Fig. 2, below; Table 1). If MyoD is required for efficient regeneration of skeletal muscle, mice lacking MyoD [designated $m d x: M y o D(-/-)$ ] should display more extensive myopathic or dystrophic changes in skeletal muscle.

As predicted, mutant $m d x: M y o D(-/-)$ mice uniformly displayed several phenotypic traits indicative of a marked increase in the penetrance of the disease (Fig. 1). By 3 to 5 months of age, $m d x: M y o D(-/-)$ mice developed a profound dorsal-ventral curvature of the spine (Fig. 1, cf. C and D), similar to the lordosis and kyphosis of patients with Duchenne muscular dystrophy, and an abnormal waddling gait characterized by weight bearing on the hocks (Fig. 1, compare A and B). The animals became progressively less active, with concomitant weight loss, before premature death at $\sim 12$ months of age. In contrast, $m d x$ mice display virtually normal external appearance and normal murine life spans of 1.5-2 years (Coulton et al. 1988).

Examination of skeletal muscle from the lumbar region of $M y O D(-/-)$ mice revealed an $\sim 17 \%$ reduction in the cross-sectional area of back muscle compared with $B A L B / c$ (hereafter referred to as wild type) back muscle (Fig. 2A,B). Moreover, $\mathrm{MyoD}(-/-)$ tibialis anterior (TA) muscle was significantly reduced in mass relative to wild-type TA by $32 \%(P<0.05)$, whereas $M y o D(-/-)$ soleus $\{\mathrm{SL}$ ) muscle was reduced by $8 \%$ (Table 1 ). These data suggest that MyoD has a role in the postnatal growth of skeletal muscle.

The $m d x$ phenotype is characterized by an $\sim 1.7$-fold increase in the mass of individual skeletal muscles compared with wild-type mice (Anderson et al. 1987; Carnwath and Shotton 1987; Coulton et al. 1988; e.g., see Fig. 2 and Table 1). Importantly, the hypertrophic response is

Table 1. Mean muscle mass from tibialis anterior and soleus hindlimb muscles from 4-month-old animals of the different genotypes

\begin{tabular}{lcc}
\hline Mouse strain & TA muscle $(\mathrm{mg})$ & SL muscle $(\mathrm{mg})$ \\
\hline Wild type & $59.3 \pm 1.4$ & $10.1 \pm 0.5$ \\
MyoD $(-/-)$ & $40.0 \pm 1.7$ & $9.3 \pm 0.5$ \\
mdx & $95.9 \pm 5.3$ & $17.9 \pm 1.6$ \\
mdx:MyoD $(-/-)$ & $45.8 \pm 4.2$ & $9.6 \pm 0.6$ \\
\hline
\end{tabular}

These data reveal the relative hypertrophy in $\mathrm{mdx}$ muscle and relative hypotrophy in $\mathrm{MyoD}(-/-)$ and $\mathrm{mdx}: \mathrm{MyoD}(-1-1$ muscle. The values above represent the mean and standard error of the mean of muscle weights from five animals $(n=10)$. 


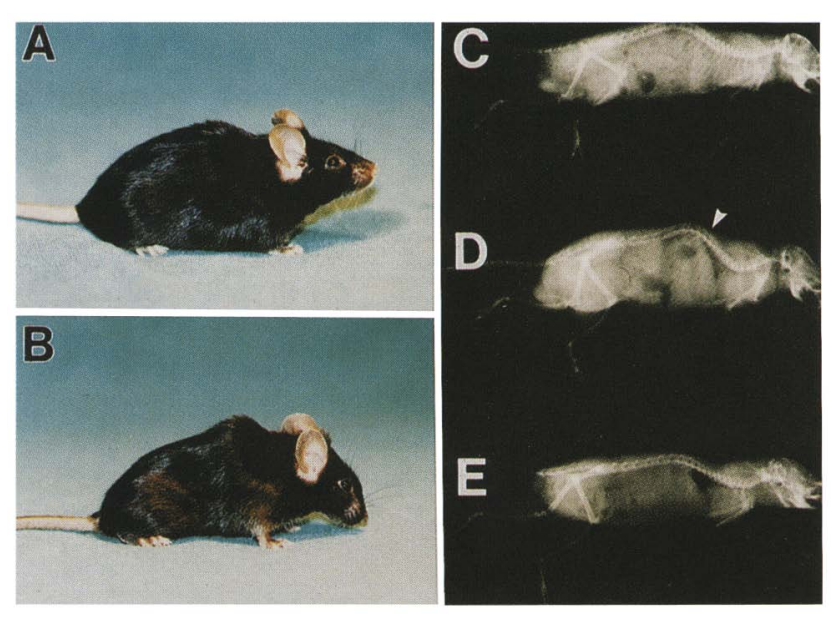

Figure 1. Increased penetrance of the $m d x$ phenotype in $m d x: M y o D(-1-)$ mice. $(A)$ The $m d x$ mouse appears morphologically normal compared with wild-type mice. $(B)$ In contrast, the $m d x: M y o D(-1-)$ mouse displays a severe dorsal-ventral curvature of the spine and increased myopathy characterized by an abnormal waddling gait and weight-bearing on the hocks. $\mathrm{x}$-Ray radiographic visualization revealed abnormal curvature of the spine (arrowhead) of $m d x: M y o D(-/-)$ mice $(D)$, compared with $m d x$ mice $(C)$, and $M y o D(-/-)$ mice $(E)$. All animals shown are 5 months of age.

reduced significantly or absent in $m d x: M y o D(-/-)$ skeletal muscle. For example, examination of skeletal muscle from the lumbar region of $m d x: M y o D(-/-)$ mice revealed an $-35 \%$ reduction in the cross-sectional area of back muscle compared with $m d x$ back muscle (Fig. 2C,D). A similar reduction was observed in the cross-sectional area of the lower leg containing TA, gastrocnemius, SL, and extensor digitorum longus muscles (not shown). In addition, the weight of TA muscle from 4-month-old $m d x: M y o D(-/-)$ mice was reduced significantly by $52 \%(P<0.05)$, relative to 4 -month-old $m d x$ TA muscle, and SL muscle was reduced significantly by $46 \%(P<0.05)$ (Table 1$)$. The diaphragm is the only muscle in $m d x$ mice that undergoes extensive dystrophic changes caused by repetitive work-related injury (Stedman et al. 1991). Examination of the $m d x: M y o D(-/-)$ diaphragm revealed extreme severity in the dystrophic changes relative to the $\mathrm{mdx}$ diaphragm, resulting in a marked reduction in muscle mass and thickness (not shown).

Muscle fibers, which have undergone a cycle of degeneration-regeneration, typically display centrally rather than peripherally located nuclei (for review, see Grounds and Yablonka-Reuvini 1993). Light microscopic examination of hematoxylin-eosin (HE)-stained thin sections of skeletal muscle from $m d x: M y o D(-/-)$ mice revealed the widespread presence of centrally located nuclei in muscle fibers, suggesting that these fibers have undergone at least some regeneration (Fig. 2, cf. $\mathrm{G}$ and $\mathrm{H}$ ).

All $m d x: M y o D(-/-)$ mice from the first and subsequent generations displayed the same degree of phenotype suggesting that the absence of MyoD is the cause of the phenotype. Furthermore, the $B A L B / c$ strain from which the $M y o D(-/-)$ mice are derived, when interbred with $m d x$ mice, did not generate the phenotype observed in $m d x: M y o D(-/-)$ mice. Therefore, we conclude that it is the lack of $M y O D$, and not some other second-site modifier gene, that causes the defect in regeneration.

The increased myopathy of skeletal muscle from $m d x: M y o D(-/-)$ mice suggests a marked decrease in their regenerative ability. Nevertheless, some regenerative potential persists, as evidenced by the presence of centrally located nuclei in $m d x: M y o D(-/-)$ muscle fibers. Taken together, these data are consistent with the hypothesis that MyoD has an important role in the embryonic formation, postnatal survival, or function of satellite cells.

\section{Impaired regeneration of $\mathrm{MyoD}(-1-\mid$ skeletal muscle}

Wild-type skeletal muscle typically undergoes several stages following injury leading to complete repair of the lesion. Within $24 \mathrm{hr}$, damaged fibers become necrotic and begin to degenerate, and large numbers of infiltrating eosinophils, neutrophils, and macrophages accumulate and remove debris from the area of damage. Satellite cellderived mpc cells invade the site, proliferate, and fuse to each other as they differentiate to form new muscle fibers within pre-existing basal lamina. By 2 weeks, every fiber is continuous and fiber calibers are comparable with undamaged muscle (for review, see Grounds and Yablonka-Reuveni 1993).

The increased penetrance of the $m d x$ phenotype in mdx:MyoD(-/-) muscle suggested that MyoD is required for efficient skeletal muscle regeneration (see Figs. 1 and 2). Therefore, to directly investigate the capacity of MyoD-deficient skeletal muscle to repair damage, we performed injury-induced regeneration experiments on $M y o D(-/-)$ animals. Briefly, the hindlimb muscle was exposed by an incision and a crush injury applied to the belly of the TA muscle with forceps cooled in liquid nitrogen (e.g., McGeachie and Grounds 1990).

Skeletal muscle from $M y o D(-/-)$ mice displayed a strikingly reduced capacity for regeneration following injury (Fig. 3, cf. A and B with $\mathrm{C}$ and D). Examination of HE-stained longitudinal sections of $M y o D(-/-)$ TA muscle 4.5 days following injury revealed the presence of high numbers of mononuclear cells and few dispersed myotubes of small size (Fig. 3B). In contrast, wild-type TA muscle displayed well-advanced regeneration with many new myofibers crossing the entire wound site (Fig. 3A). Examination of longitudinal sections of MyoD (-/-) TA muscle 2 weeks after injury revealed mononuclear cells persisting in an atypical fashion as well as limited regeneration, as evidenced by the presence of thin myofibers at the site of injury (Fig. 3D). By comparison, wild-type muscle exhibited virtually complete myofiber regeneration by 2 weeks (Fig. $3 \mathrm{C}$ ). The $B A L B / c$ strain was used as wild-type control in these experiments because $\mathrm{BALB} / \mathrm{c}$ muscle exhibits the least efficient regeneration among the different mouse strains 
Figure 2. Attenuated hypertrophy and increased myopathy in $m d x: M y o D(-/-)$ skeletal muscle. HE-stained sections through the lumbar region of the lower back in wild-type $(A, E), M y o D(-/-)(B, F)$, $m d x(C, G)$, and $m d x: M y o D(-/-)(D, H)$ mice. MyoD-deficient mice exhibited a reduced cross-sectional area of muscle relative to wild-type (cf. $A$ and $B$ ) and $m d x$ mice (cf. $C$ and $D$ ). Higher magnification of these sections revealed increased numbers of interstitial mononuclear cells and reduced fiber calibers in $m d x: M y o D(-1-)$ muscle (cf. $G$ and $H$ ). Note the presence of centrally located nuclei in $m d x: M y o D(-/-)$ fibers, suggesting that some degree of regeneration has occurred (arrows).
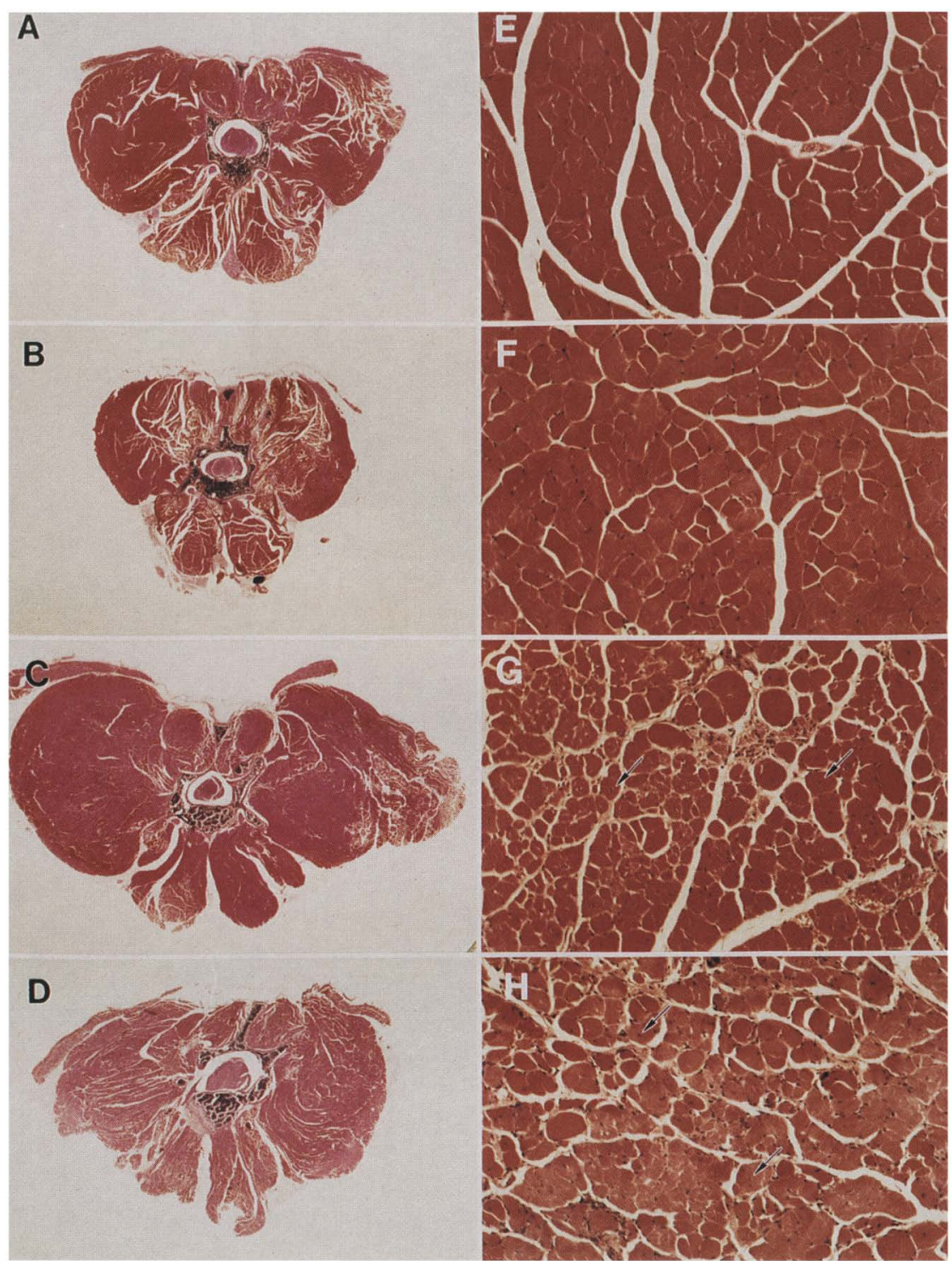

(e.g., Mitchell et al. 1992). Like $M y o D(-/-$ ) muscle, $m d x: M y o D(-/-)$ muscle was similarly deficient in regenerative proficiency following injury (not shown).

These results strongly support the hypothesis that the defect in skeletal muscle regeneration in $M y o D(-/-)$ mice is at the level of satellite cell formation, survival, or function. Furthermore, these data support the contention that the increased severity of the phenotype observed in $m d x: M y o D(-/-)$ mice is a consequence of decreased regenerative ability.

\section{Enumeration of satellite cells and satellite cell-derived myoblasts}

The increased severity of $m d x$ phenotype in the $m d x: M y o D(-/-)$ mouse, and the limited regeneration of skeletal muscle from $M y o D(-/-)$ mice following injury, indicated that MyoD has a unique role in satellite cell biology. One possibility was that $M y o D$-deficient muscle contained reduced numbers of stem cells. To address this question, we assessed whether quiescent satellite cells were present by electron microscopic examination of sectioned skeletal muscle and enumerated the total number of cells with myogenic potential following culture of primary cells derived from skeletal muscle. Unexpectedly, these experiments provided evidence for markedly increased numbers of myogenic stem cells in MyoD $(-/-)$ and $m d x: M y o D(-/-)$ muscle.

Quiescent satellite cells can be reliably identified by electron microscopy by their morphological appearance and location external to the muscle-fiber sarcolemma and beneath the basal lamina encasing the fiber (Schultz 1976). Satellite cells comprise $\sim 32 \%$ of sublaminal nuclei in newborn mice, and this proportion declines to $<5 \%$ by 8 weeks of age (for review, see Bischoff 1994). TA muscle from 4-month old wild-type, $M y o D(-/-)$, 

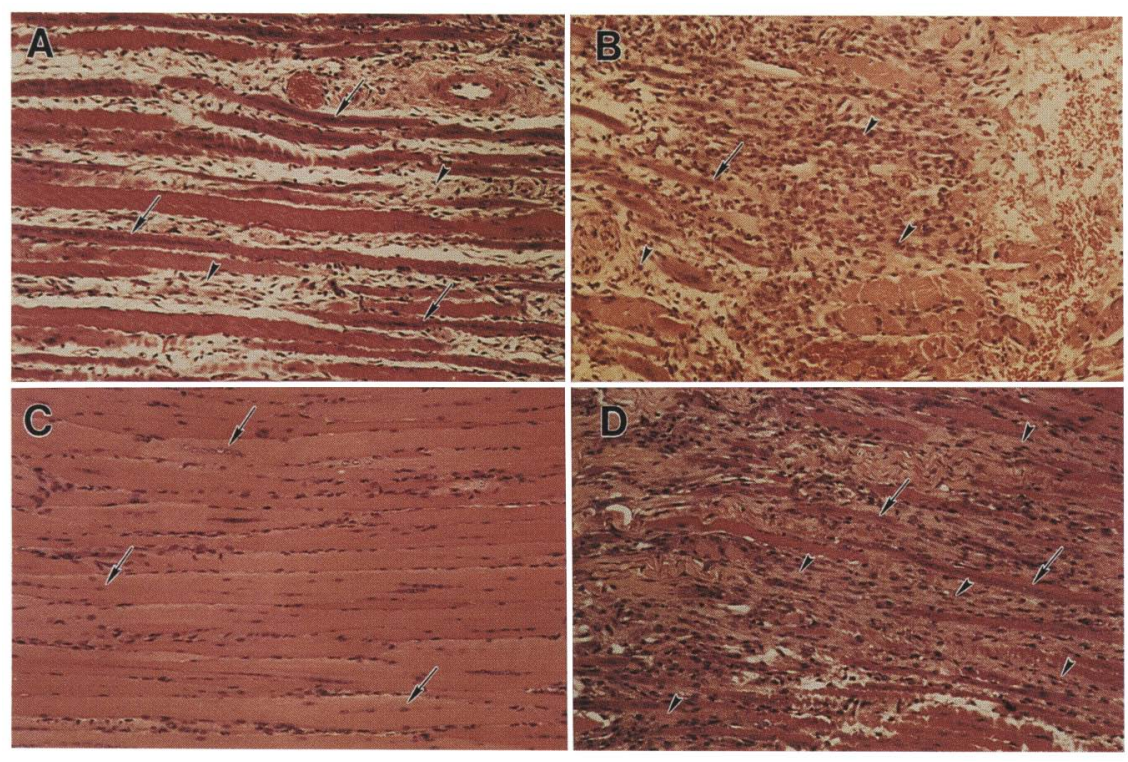

Figure 3. Impaired regeneration of MyoD(-1-) skeletal muscle. Longitudinal-sections of HE-stained TA muscle sampled 4.5 days $(A, B)$, and 2 weeks following crush-induced injury $|C, D|$. (A) Wild-type muscle 4.5 days following injury displayed a robust regenerative capacity with well-advanced myofibrogenesis, as evidenced by centrally located nuclei farrows), in addition to putative mononuclear mpc (arrowhead). (B) MyoD(-/-) muscle 4.5 days following injury exhibited markedly reduced levels of regeneration with many mononuclear cells present (arrowheads), as well as small myotubes (arrows). (C) Wild-type muscle 2 weeks following injury, appeared similar to undamaged skeletal muscle except for the presence of centrally located nuclei (arrows) and reduced fiber calibers. $(D)$ MyoD $(-/-)$ muscle 2 weeks following injury exhibited many small caliber myotubes (arrows) and unusually high numbers of mononulear cells (arrowheads). $m d x$, and $m d x: M y o D(-/-)$ mice were processed for transmission electron microscopic examination. Analysis of these sections clearly revealed the presence of morphologically normal satellite cells in TA muscle of all genotypes (Fig. 4).

Electron microscopy also allowed an approximation of the proportion of quiescent satellite cells in vivo as determined by counting the ratio of sublaminar mononuclear cells to intrafibrillar nuclei in representative fields (Table 2). Satellite cells made up $2.9 \%$ of the sublaminar nuclei in $M y o D(-1-)$ TA muscle, $3.3 \%$ in $m d x$ TA muscle, and $4.4 \%$ in wild-type TA muscle (Table 2). These values are typically considered within the normal range (Schultz 1976; Bischoff 1994). In contrast, we observed a 2.5 -fold increase in the proportion of satellite cells in mdx:MyoD(-/-) TA muscle, where satellite cells made up $8.3 \%$ of sublaminal nuclei (Table 2 ). Because of the limited sample size, this experiment can only reveal trends rather than significant differences. However, these data suggest that quiescent satellite cells, as identified by morphology and position, are present in normal proportions in $M y o D(-/-)$ muscle and in elevated proportions in $m d x: M y o D(-/-)$ muscle.

Electron microscopy only allows the identification of satellite cells when they are located between the sarcolemma and basal lamina, and not outside this position (Grounds 1991). To quantitate the relative proportions of muscle stem cells between animals of different genotypes, populations of myoblasts were cultured in vitro from primary cultures derived from wild-type, MyoD (-/-), $m d x$, and $m d x: M y o D(-/-)$ hindlimb muscle. Muscles were weighed, minced, dispersed enzymatically, filtered, and plated onto collagen-coated dishes in medium supplemented with fetal calf serum and basic fibroblast growth factor (bFGF) (after Rando and Blau 1994). After 4 days of culture, total cell yield (myoblasts plus fibroblasts) per milligram of muscle was determined, and the relative proportion of myoblasts assessed by indirect immunochemical staining using monospecific antisera DE-U-10, reactive to desmin /see

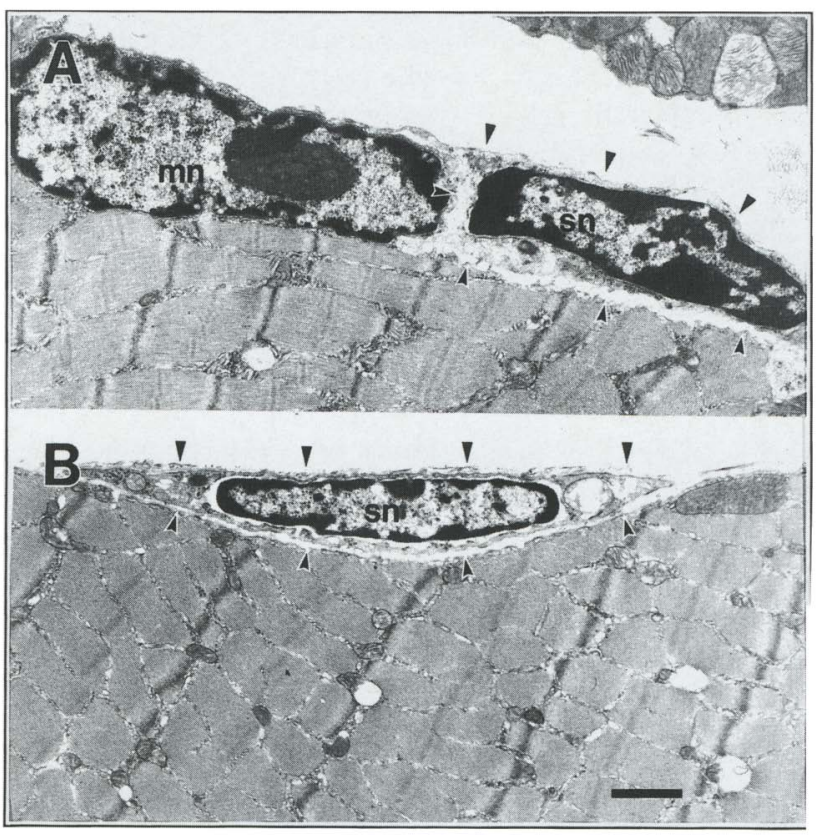

Figure 4. Satellite cells in $M y o D(-/-)$ skeletal muscle. Electron microscopic examination of sections revealed the presence of morphologically normal satellite cells in $M y o D(-/-)$ TA muscle located external to the sarcolemma lupward arrowheads) and the basal lamina (downward arrowheads), and outside the myofiber membrane. Enumeration suggested about normal proportions of satellite cells were present in $\mathrm{MyoD}(-1-)$ muscle, and potentially elevated proportions in $m d x: M y o D(-1-)$ muscle (see Table 2). (mn) Muscle cell nucleus; (sn) satellite cell nucleus; Bar, $1 \mu \mathrm{M}$. 
Table 2. MyoD(-/-) muscle contains elevated numbers of myogenic cells

\begin{tabular}{|c|c|c|c|c|c|}
\hline Genotype & $\begin{array}{l}\text { Percent satellite } \\
\text { cells in vivo }\end{array}$ & $\begin{array}{l}\text { Total number } \\
\text { cells } / \mathrm{mg} \\
\text { wet weight }\end{array}$ & $\begin{array}{l}\text { Percent cells } \\
\text { desmin }+\mathrm{ve}^{\mathrm{c}}\end{array}$ & $\begin{array}{l}\text { Total number } \\
\text { myoblasts } / \mathrm{mg} \\
\text { wet weight }\end{array}$ & $\begin{array}{l}\text { Percent nuclei } \\
\text { MHC + ve } e^{\mathrm{e}}\end{array}$ \\
\hline Wild type & 4.4 & $1531 \pm 174$ & $22.4 \pm 1.8$ & 343 & $6.5 \pm 0.8$ \\
\hline MyoD $1-1-1$ & 2.9 & $3356 \pm 599$ & $18.5 \pm 1.3$ & 621 & $11.0 \pm 1.8$ \\
\hline$m d x$ & 3.3 & $1506 \pm 174$ & $4.8 \pm 0.7$ & 72 & N.D. \\
\hline$m d x: M y o D(-1-)$ & 8.3 & $8314 \pm 1509$ & $11.7 \pm 1.4$ & 972 & N.D. \\
\hline
\end{tabular}

The values represent the mean and standard error of the mean for five independent experiments $|n>2000|$. (N.D. $\mid$ Not determined. ${ }^{a}$ The proportion of satellite cells in TA muscle as determined by electron microscopy $(n>200)$.

${ }^{\mathrm{b}}$ After 4 days in culture, the total number of cells recovered per mg of muscle was determined by monodispersing the cultures and counting cells in a hemocytometer.

${ }^{\mathrm{c}}$ The proportion of myoblasts was determined by immunodetection with anti-desmin antibody DE-U-10.

${ }^{\mathrm{d}}$ The relative number of cells with myogenic potential per mg wet weight was determined by multiplying the percent $\left({ }^{\mathrm{c}}\right)$ by the total number of cells recovered $(\mathrm{b})$.

${ }^{\mathrm{e}}$ The proportion of differentiated myocytes was determined by immunodetection with anti-myosin heavy chain antibody MF20.

Fig. 5). Desmin is an intermediate filament protein expressed in mpc in vivo, and myoblasts in vitro, but not satellite cells (George-Weinstein et al. 1993; Bischoff 1994).

Immunochemical analysis revealed that the percentage of myoblasts observed in 4-day cultures derived from wild-type skeletal muscle was $22.4 \%$, whereas the percentage of myoblasts in cultures from $M y o D(-/-)$ muscle was $18.5 \%$. However, because the total yield of cells per milligram was increased 2.2-fold in the $M y o D(-/-)$ muscle relative to wild-type muscle $(P<0.05)$, the number of myogenic cells recovered per milligram of muscle was therefore increased 1.8-fold in $M y o D(-/-)$ muscle relative to wild-type muscle (Table 2). The percentage of myoblasts observed in cultures from $m d x$ muscle was $4.8 \%$, whereas the percentage of myoblasts in cultures from $m d x: M y o D(-/-)$ muscle was $11.7 \%$. Similarly, because the total number of cells per muscle weight was increased 5.5-fold in the $m d x: M y o D(-/-)$ muscle relative to $m d x$ muscle $(P<0.05)$, the number of myogenic cells recovered per milligram was therefore increased 13 fold in $m d x$ : $M y o D(-/-)$ muscle relative to $m d x$ muscle (Table 2).

Interestingly, wild-type and $M y o D$ mutant myoblasts differed both in morphological appearance and intensity of anti-desmin antibody labeling. As described elsewhere (e.g., Ontell et al. 1992), $>90 \%$ of the desmin-labeled myoblasts from wild-type muscle were typically spherical, phase dark, and appeared to express high levels of desmin (Fig. 5A). In contrast, the majority of myoblasts from $M y o D(-/-)$ muscle displayed a flat stellate morphology and expressed lower levels of desmin (Fig. 5B).

The differentiation potential of myoblasts derived from primary cultures from wild-type and $M y o D(-/-)$ muscle was also investigated. Cultured myoblasts were expanded under growth conditions for 1 week and trans-
Figure 5. Cultured myoblasts from primary cultures of satellite cells. Immunochemical detection of desmin-expressing myoblasts from wild-type $(A)$ and $M y o D$ deficient $(B)$ muscle indicated that myogenic cells (arrows) were present in elevated proportions in $M y o D(-/-)$ skeletal muscle (see Table 2). Differentiated myocytes expressing myosin heavy chain induced from myoblasts derived from wildtype $(C)$ and $M y o D$-deficient $(D)$ muscle displayed similar morphology and were found at similar frequencies (see Table 2). Myoblasts were detected with anti-desmin antibody DE-U-10, and myocytes with anti-myosin heavy chain antibody MF20. Magnification in $A$ and $B$ is twice that in $C$ and $D$.

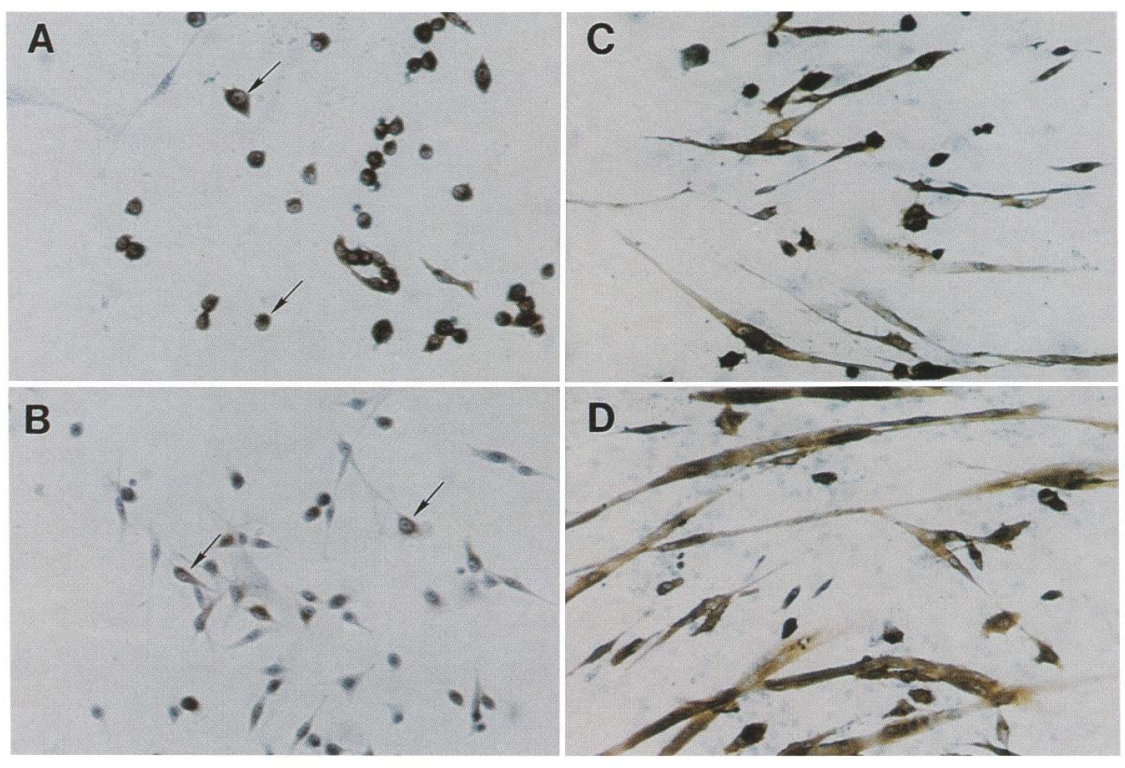


ferred to differentiation medium for a second week. Differentiated myocytes were detected using indirect immunochemistry with mouse monoclonal antibody MF20 reactive with striated muscle myosin heavy chain (Bader et al. 1982). MyoD mutant myocytes were morphologically indistinguishable from wild-type myocytes (Fig. 5, cf. C and D). The proportion of nuclei within immunoreactive myocytes was found to be $11.0 \%$ in MyoD(-/-) cultures and $6.5 \%$ in wild-type cultures (Table 2). The increased proportions of differentiated $M y o D$-deficient myocytes observed in vitro $(P<0.05)$ suggests that desmin may be expressed below the limit of detection in some portion of MyoD mutant myoblasts; hence, the numbers of myogenic cells per milligram in $M y o D(-/-)$ muscle may represent an underestimate (Table 2).

The increased numbers of myoblasts recovered from $M y o D(-/-)$ muscle raised the possibility that myoblasts lacking $M y O D$ may display increased rates of proliferation. To determine the doubling time of myoblasts in vitro, we measured the increase in numbers of desmin-staining cells over a period of 8 days. Importantly, we observed the in vitro doubling time of myoblasts derived from $M y O D(-/-)$ muscle to be about three-fold longer than wild-type myoblasts. Furthermore, purified populations of $M y O D(-/-)$ myoblasts incorporated three-fold less tritiated thymidine. These observations support the notion that MyoD has an important role in positively inducing myoblast proliferation. Furthermore, these data suggest that we have underestimated the numbers of myoblasts isolated from MyoD(-/ - ) muscle by at least two-fold.

\section{In vivo proliferation of $\mathrm{MyoD}(-/-\mid$ myogenic cells}

Skeletal muscle from $m d x: M y o D(-/-)$ mice relative to $m d x$ mice contained a 2.5 -fold increase in numbers of satellite cells by morphology and position (Fig. 4, Table 2 ), and at least a 13-fold increase in numbers of myogenic cells per milligram of muscle (Fig. 5; Table 2). If MyoD $(-/-)$ mpc proliferate normally in vivo, we should observe a 13 -fold increase in the proportion of cells undergoing cell division in $m d x: M y o D(-/-)$ muscle relative to $m d x$ muscle. Therefore, we examined cellular proliferation in vivo in $m d x: M y o D(-/-)$ muscle containing elevated numbers of myogenic cells under conditions that normally lead to high-level satellite cell activation, namely by performing injury-induced regeneration as described above. We examined the in vivo proliferative potential of myogenic cells in $m d x$ vs. $m d x: M y o D(-/-)$ skeletal muscle using two independent approaches.

Replicating cells express PCNA at high levels throughout $S$ phase (e.g., Bravo et al. 1987). Consequently, immunostaining of PCNA in sections of skeletal muscle with monospecific antibodies allows detection of myogenic cell proliferation (Johnson and Allen 1993). The TA muscle in 4-month-old $m d x$, and $m d x: M y o D(-/-)$ mice was subjected to crush injury, and $24 \mathrm{hr}$ after injury, samples were prepared for immunohistochemical staining with antibody reactive to PCNA $(n=3)$. Examination of PCNA expression $24 \mathrm{hr}$ after injury should allow detection of muscle stem-cell activation. Enumeration of peripherally located nuclei expressing PCNA in surviving areas immediately adjacent the site of injury revealed similar proportions of PCNA-expressing nuclei in $m d x$ and $m d x: M y O D(-/-)$ muscle (Fig. 6A,B). Because $m d x: M y o D(-/-)$ muscle contains 13-fold higher numbers of myogenic cells relative to $m d x$ muscle $(\mathrm{Ta}-$ ble 2), these data therefore suggest that $M y o D$-deficient satellite cells exhibit reduced rates of activation, or entry into the cell cycle.

In a second approach, mice were injected intraperitonealy with $2.0 \mu \mathrm{Ci}$ /gram of body weight of tritiated thy-
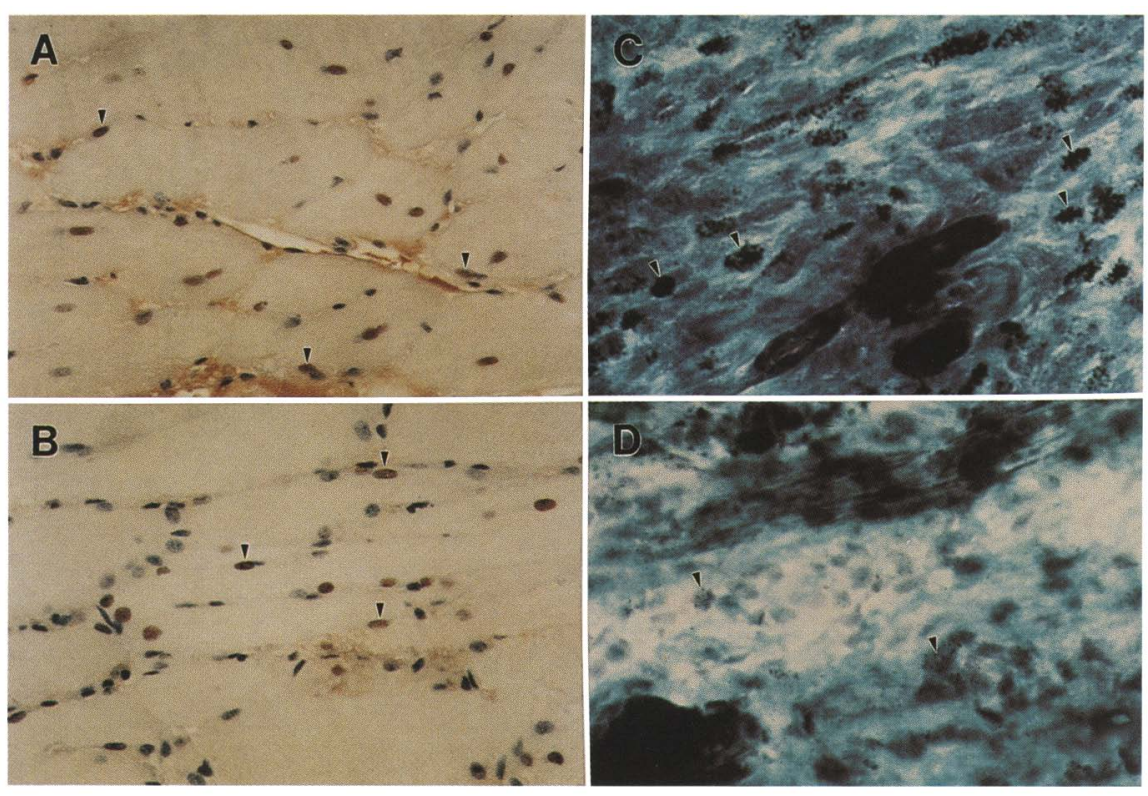

Figure 6. Reduced cellular proliferation during regeneration of $M y o D(-/-)$ muscle. Samples were prepared for immunohistochemical staining with an antibody reactive to PCNA $24 \mathrm{hr}$ following injury to detect satellite-cell activation $(A, B)$. In surviving areas immediately adjacent the site of injury, $\sim 10 \%$ of peripherally located nuclei expressed PCNA in both $m d x(A)$ and $m d x: M y o D(-1-)$ muscle $|B|$ even though $m d x: M y o D(-1-)$ muscle contains 13-fold higher numbers of myogenic cells (see Table 2). Mice were injected with tritiated thymidine 3.5 days following injury, and samples were prepared for autoradiography $24 \mathrm{hr}$ later $(C, D)$. TA muscle from $m d x$ mice $(C)$ displayed abundant nuclei decorated heavily with silver grains, whereas TA muscle from $m d x: M y o D(-/-)$ mice $(D)$ displayed only rare nuclei decorated lightly with silver grains. 
midine 3 days after injury, and tissue samples were prepared for autoradiography $24 \mathrm{hr}$ later $(n=5)$. This approach allows detection of $\mathrm{mpc}$ replication during injuryinduced muscle regeneration (e.g., Anderson et al. 1987; McGeachie and Grounds 1990). Four and a half days following injury, mdx TA muscle displayed abundant nuclei decorated heavily with silver grains, indicating that high numbers of mpc cells were cycling following injection of the labeled thymidine (Fig. 6C). Furthermore, in situ hybridization of companion sections revealed that $30 \%$ of cells expressing myogenin were heavily labeled (data not shown). In contrast, $m d x: M y o D(-/-)$ TA muscle displayed only low numbers of nuclei decorated lightly with silver grains and no cells decorated heavily with silver grains, indicating that the majority of myogenic cells had not passed through $S$ phase (Fig. 6D). Only rare myogenin-expressing cells were observed, and only $12 \%$ of these were labeled lightly (data not shown).

One possible explanation for the apparent decrease in mpc proliferation during regeneration in $M y o D(-/-)$ muscle, was that $M y o D$ mutant mpc may undergo programmed cell death. We therefore employed the terminal transferase-mediated dUTP-biotin nick end labeling (TUNEL) in situ staining technique (Gavrieli et al. 1992) to determine whether regenerating $M y o D(-/-)$ muscle contained elevated numbers of apoptotic nuclei. We observed only very low numbers of apoptotic nuclei at similar frequencies in all the muscle genotypes /data not shown). Therefore, we conclude that MyoD-deficient myogenic cells do not inappropriately undergo apoptosis.

MyoD-deficient satellite cells appear to exhibit decreased rates of activation following trauma, and their mpc daughter cells display a markedly reduced proliferative potential in vivo as assessed by tritiated thymidine incorporation. Paradoxically, however, we observed a marked increase in the total number of cells with myogenic potential (Table 2). We interpret these data to suggest that the apparent increase in numbers of myogenic cells is a consequence of increased muscle stem-cell selfrenewal because of an altered propensity for self-renewal rather than progression through the developmental program.

\section{Discussion}

Mice lacking $M y o D$ are viable and display no obvious defects in function, morphology, or gene expression in skeletal muscle (Rudnicki et al. 1992). Interbreeding of $M y o D$ and $M y f-5$ mutant mice clearly established that these factors functionally substitute for one another during embryonic development, because in the absence of both factors, no myoblasts or myofibers are formed (Rudnicki et al. 1993). The apparently normal phenotype of MyoD mutant mice and the early expression of MyoD following satellite-cell activation (Yablonka-Reuveni and Rivera 1994; Smith et al. 1994) led us to hypothesize that $M y o D$ may have an important role in the postnatal growth and regeneration of skeletal muscle.

In this study we show that adult mice lacking $M y o D$ display marked deficits in satellite cell function. MyoD (-i-) mice interbred with $m d x$ mice exhibited increased penetrance of the $m d x$ phenotype characterized by reduced muscle hypertrophy and increased myopathy leading to premature death (Figs. 1 and 2). Consistent with this observation, skeletal muscle regeneration in $M y O D(-1-)$ mice was strikingly impaired following application of an injury to the TA muscle (Fig. 3). Electron microscopic examination of $M y o D$-deficient muscle revealed the presence of morphologically normal satellite cells (Fig. 4), and enumeration of myoblasts from primary cultures revealed elevated levels of cells with myogenic potential in $M y o D(-/-)$ and mdx:MyoD(-/-) muscle (Fig. 5, Table 2). Moreover, cultured $M y o D(-/-)$ myoblasts displayed reduced rates of proliferation. Furthermore, cellular proliferation during regeneration of $m d x: M y o D(-/-)$ muscle is dramatically reduced (Fig. 6). Therefore, we conclude that MyoD has a unique and novel role in satellite cells and that Myf-5 does not substitute for this function. Taken together, our results have important implications for understanding the genetic mechanisms that regulate the skeletal-muscle stem-cell program in postnatal growth and regeneration.

Satellite cells have been postulated to represent a compartment of self-renewing stem cells distinct from their proliferating mpc descendants that form a transient population following satellite cell activation. For example, whereas mpc express desmin, $\alpha 7$-integrin, neural cell adhesion molecule (NCAM), and MRFs, satellite cells do not (for review, see Bischoff 1994). We propose that MyoD expression is required in vivo for stem cells to enter the mpc proliferative phase that precedes terminal differentiation (Fig. 7). According to this model, the apparent increase in numbers of myogenic cells in $M y o D$ deficient muscle is caused by an increased propensity for satellite cell self-renewal rather than progression through the developmental program. Consistent with this hypothesis, our data indicate that $M y o D(-/-)$ muscle contains increased numbers of cells with myogenic potential (Table 2) and that these cells exhibit reduced proliferation both in vitro and during injury-induced muscle regeneration (Fig. 6).

The requirement for MyoD in the adult muscle stemcell program may be direct, for example, MyoD up-regulation in activated satellite cells is required for expression of genes essential for normal mpc proliferation and differentiation. Alternatively, the requirement for MyoD may be indirect, for example, MyoD may be required in myofibers for the expression of growth factors essential for activating satellite cells or stimulating mpc proliferation. Although our experiments cannot discriminate between these two possibilities, the observations that MyoD is expressed at very low levels in adult myofibers, and is strongly up-regulated only in satellite cells following denervation, injury, or other trauma (e.g., Fuchtbauer and Westphal 1992; Bischoff 1994; Smith et al. 1994; Yablonka-Reuveni and Rivera 1994), strongly supports the notion that the requirement is cell autonomous. Transplantation of $M y o D(-/-)$ myoblasts into $\gamma$-irradi- 


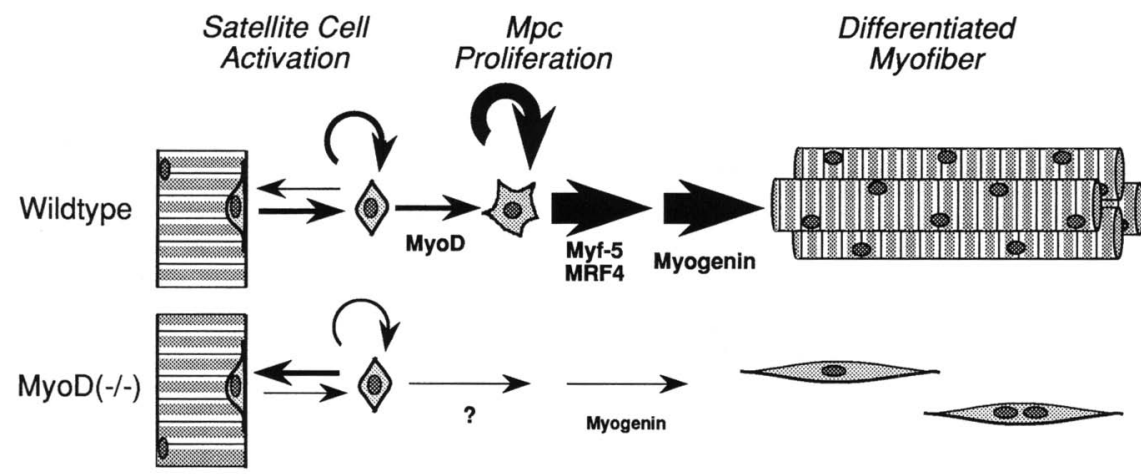

Figure 7. A unique role for MyoD in satellite-cell function. Our data suggest a model in which up-regulation of MyoD is required for satellite cells to enter the mpc proliferative phase that precedes terminal differentiation. Normally, MyoD is up-regulated with entry into the cell cycle, Myf -5 and MRF4 are expressed at intermediate times, and myogenin is expressed last during the time associated with differentiation (Smith et al. 1994; Yablonka-Reuveni and Rivera 1994). In this model, the absence of MyoD leads to an apparent increase in numbers of myogenic cells as a consequence of increased muscle stem-cell self-renewal because of an altered propensity for self-renewal rather than progression through the developmental program. ated wild-type muscle should clarify whether the requirement for MyoD is cell autonomous.

MyoD is expressed early during the program as satellite cells enter the cell cycle and become mpc, Myf-5 and MRF4 are expressed at intermediate times, and myogenin is expressed on terminal differentiation (Smith et al. 1994; Yablonka-Reuveni and Rivera 1994). The coexpression of MyoD with PCNA suggests that MyoD has an early role in the satellite cell developmental program. Such a role appears inconsistent with the well-established capacity of MyoD to arrest the proliferation of cultured cells (e.g., see Olson 1992) but is consistent with the expression of Myf-5 and MyoD in proliferating mpc during embryogenesis and in proliferating myoblast cell lines (for review, see Rudnicki and Jaenisch 1995). Several possible roles can be hypothesized. (1) The induction of MyoD is required for the specification of mpc from satellite cells; (2) expression of MyoD positively regulates mpc proliferation; and (3) MyoD expression acts to counter the proliferation induced by activation and leads to differentiation. Clearly, identification of the genes that are regulated by MyoD in this context should elucidate the function of MyoD in satellite cells.

Satellite cells are postulated to arise from a unique cell population that forms late in development and is separate from the lineages believed to give rise to primary and secondary myofibers (Cossu and Molinaro 1987; Stockdale 1992). Our results indicate that MyoD mutant muscle contains morphologically normal satellite cells in elevated numbers as evidenced by their recovery in cell culture (Fig. 4; Table 2). Therefore, these data suggest that $\mathrm{MyoD}$ is not required for the determination of the satellite-cell lineage during embryonic development. Potentially, other MRFs, for example, Myf-5, could be considered candidates for such a role, but at this time the genetic mechanisms that determine the embryonic origin of satellite cells remain unknown.

Relatively little is known of the pathways regulating the quiescence, activation, and proliferation of satellite cells. Clearly, our data indicate that induction of MyoD expression is required for appropriate satellite cell func- tion. Transgenic and transfection analysis of $M y o D$ regulatory sequences has indicated that at least two enhancers are involved in regulating $M y O D$ transcription. Between -18 and $-22 \mathrm{~kb}$ upstream from the transcription start site there is a strong enhancer that is capable of directing appropriate muscle-specific expression /Goldhamer et al. 1992) and has a conserved core sequence of $258 \mathrm{bp}$ that is functional even after mutation of E-boxes (Goldhamer et al. 1995). A second, less robust MyoD enhancer between -4.73 and $-5.39 \mathrm{~kb}$ upstream from the transcription start site (Tapscott et al. 1992) can also direct appropriate myotomal-specific expression (Asakura et al. 1995). Whether either of the two MyoD enhancers is required for appropriate induction of MyoD following satellite cell activation remains to be determined. However, such an analysis should elucidate the regulatory pathways involved in satellite cell activation.

The interbreeding of $m d x$ and MyoD mutant mice has revealed a role for $\mathrm{MyoD}$ in the satellite cell program and has provided an experimental animal model that more closely resembles Duchenne and Becker muscular dystrophy. Except in the diaphragm, $m d x$ mice do not display the muscle fiber loss and extensive interstitial fibrosis observed in humans (Stedman et al. 1991). Moreover, unlike $m d x$ muscle, human dystrophin deficiency leads to severe reduction in satellite cell populations and mpc proliferative potential (Webster and Blau 1990). Therefore, the reduced proliferative potential of myogenic cells and the increased myopathic phenotype suggests that the $m d x: M y o D(-/-)$ mice will be a useful system for a wide variety of studies relevant to the understanding of different aspects of muscular dystrophy. For example, physiological studies of mdx:MyoD $(-/-)$ skeletal muscle, determination of isometric twitch kinetics, metabolic perturbations, and so forth, will allow insight into the progressive degenerative consequences produced as a result of impaired satellite cell function. Importantly, the $m d x: M y o D(-/-)$ mice should be a useful model for testing the impact of different viral or DNA gene transfer, myoblast transfer, or pharmacologic treatment modalities. Clearly, the more severe pheno- 
type evident in $m d x: M y o D(-/-)$ mice will allow a more relevant testing of the biological efficacy of these different approaches.

\section{Materials and methods}

Induced regeneration of skeletal muscle

To induce regeneration of skeletal muscle, the TA muscle was subjected to a single freeze-crush injury as described by McGeachie and Grounds (1990). Briefly, mice were anesthetized through an intraperitoneal injection of Avertin $(0.016 \mathrm{ml}$ of $2.5 \%$ avertin/gram body weight). An incision was made (frontal portion of lower hindlimb, knee joint to ankle joint) exposing the TA muscle and a pair of serrated forceps (jaw width $2.5 \mathrm{~mm}$ ), cooled in liquid nitrogen, were used to apply a crush injury to the TA. The contralateral limb was used as an undamaged control.

\section{Cell culture and immunodetection of desmin and myosin}

Satellite cell-derived myoblasts were isolated from the skeletal muscle of the lower hindlimb of adult mice as described previously (Rando and Blau 1994). Growth medium consisted of Ham's F-10 (GIBCO BRL) supplemented with $20 \%$ fetal calf serum (GIBCO BRL), $2.5 \mathrm{ng} / \mathrm{ml}$ of bFGF (Boehringer Mannheim), $200 \mathrm{Units} / \mathrm{ml}$ of penicillin (GIBCO BRL), $200 \mu \mathrm{g} / \mathrm{ml}$ of streptomycin (GIBCO BRL), and $0.002 \%$ Fungizone (GIBCO BRL). Differentiation medium consisted of Dulbecco's modified Eagle medium (DMEM) (GIBCO BRL) supplemented with 2\% horse serum (GIBCO BRL) and antibiotics listed above. Growth medium was changed twice every day, and differentiation medium every second day.

Cultured myoblasts were detected with mouse anti-desmin antibody DE-U-10 (Sigma, St. Louis, MO) after 4 days of culture. Differentiated myocytes were detected with mouse anti-myosin heavy chain antibody MF20 (Developmental Studies Hybridoma Bank, Iowa City, IA) in primary cells cultured for 7 days in growth medium and then switched to differentiation medium for 7 days. Briefly, immunochemistry was performed as follows. Culture dishes rinsed in PBS were fixed in $90 \%$ methanol for 5 min at $-20^{\circ} \mathrm{C}$, rinsed three times in PBS containing $5 \%$ skim milk powder, incubated with primary antibody $(1: 10$ dilution $)$ for $1 \mathrm{hr}$, and rinsed three times with PBS. Culture dishes were then incubated with secondary antibody lgoat-anti-mouse IgG HRP conjugate (Bio-Rad) diluted $1: 1000$ ] for $1 \mathrm{hr}$, rinsed three times in PBS, and developed with $0.6 \mathrm{mg} / \mathrm{ml}$ of diaminobenzidine (Sigma) for $20 \mathrm{~min}$. Nuclei were counterstained with Gill's hematoxylin.

\section{Histological analysis}

TA muscle was prepared for electron microscopy by fixation in $2 \%$ glutaraldehyde $/ 0.1 \mathrm{M}$ cacodylate $(\mathrm{pH} 7.4)$, for $2 \mathrm{hr}$ at $4^{\circ} \mathrm{C}$ and processed using standard procedures as descibed previously $(\mathrm{Ka}$ blar 1995|. Randomly chosen fields for each section were viewed and assessed with a Jeol 1200 EX Biosystem transmission electron microscope. TA muscle was prepared for immunohistochemistry by overnight fixation in $4 \%$ paraformaldehyde at $4^{\circ} \mathrm{C}$. Immunohistochemistry, as described previously (Rudnicki et al. 1992) was performed on paraffin-embedded TA sections with mouse monoclonal PC10 antibody reactive with PCNA (Dakopatts|. For HE staining, muscles were fixed for 1 week in $10 \%$ formalin and prepared as described previously (Bancroft and Stevens 1990).

Detection of cell proliferation by tritiated thymidine incor- poration in vivo was performed as described previously (Anderson et al. 1987/. Mice were intraperitonealy injected 3.5 days following injury with tritiated thymidine (Amersham) at a dose of $2.0 \mu \mathrm{Ci} /$ gram body weight. Frozen sections were prepared 4.5 days following injury for autoradiography. Sections were fixed in $10 \%$ formalin for $10 \mathrm{~min}$, rinsed, dipped in $\mathrm{K} 5$ emulsion (Ilford), and exposed for 6 weeks at $4^{\circ} \mathrm{C}$. Slides were developed in D-19 (Kodak, Rochester, NY), fixed, and counterstained in Gomori's trichrome stain.

\section{Acknowledgments}

We thank John Hassell, William Muller, Luc Sabourin, and Jim Smiley for critical comments on the manuscript. This work was supported by grants to M.A.R. from the Medical Research Council of Canada, and the Muscular Dystrophy Association, and to I.E.A. from the P.H.T. Thorlakson Foundation and the Manitoba Health Research Council. L.A.M. held a Postdoctoral Fellowship from the Natural Science and Engineering Research Council of Canada and is currently a Postdoctoral Fellow of the Medical Research Council of Canada. K.L.G. held a combined Postdoctoral Fellowship from the Muscular Dystrophy Association of Canada and Medical Research Council of Canada. M.A.R. is a Research Scientist of the National Cancer Institute of Canada, and is a member of the Canadian Genetic Disease Network of Excellence.

The publication costs of this article were defrayed in part by payment of page charges. This article must therefore be hereby marked "advertisement" in accordance with 18 USC section 1734 solely to indicate this fact.

\section{References}

Ahn, A.H. and L.M. Kunkel. 1993. The structural and functional diversity of dystrophin. Nature Genet. 3: 283-291.

Anderson, J.E., W.K. Ovalle, and B.H. Bressler. 1987. Electron microscopic and autoradiographic characterization of hindlimb muscle regeneration in the $\mathrm{mdx}$ mouse. Anat. Rec. 219: 243-257.

Asakura, A., G.E. Lyons, and S.J. Tapscott. 1995. The regulation of MyoD gene expression: Conserved elements mediate expression in embryonic axial muscle. Dev. Biol. 171:386398.

Bader, D., T. Masaki, and D.A. Fischmann. 1982. Immunochemical analysis of myosin heavy chain during avian myogenesis in vivo and in vitro. I. Cell Biol. 95: 763-770.

Bancroft, J.D. and A. Stevens. 1990. Theory and practice of histological techniques. Churchill Livingston, Edinburgh, UK.

Bischoff, R. 1994. The satellite cell and muscle regeneration, In Myology 2nd ed. (ed. A.G. Engel and C. Franzini-Armstrong), pp. 97-133. McGraw-Hill, New York, NY.

Braun, T., M.A. Rudnicki, H.H. Arnold, and R. Jaenisch. 1992. Targeted inactivation of the mouse regulatory gene Myf5 results in abnormal distal rib development and early postnatal death in homozygous mouse mutants. Cell 71: 369-382.

Braun, T., E. Bober, M.A. Rudnicki, R. Jaenisch, and H.H. Arnold. 1994. MyoD expression marks the onset of skeletal myogenesis in homozygous Myf-5 mutant mice. Development 120: 3083-3092.

Bravo, R., R. Frank, P.A. Blundell, and H. MacDonald-Bravo. 1987. Cyclin/PCNA is the auxiliary protein of DNA polymerase- $\delta$. Nature 326: 515-517.

Buckingham, M. 1992. Making muscle in mammals. Trends Genet. 8: 144-148.

Carnwath, I.W. and D.M. Shotton. 1987. Muscular dystrophy in 
the mdx mouse: Histopathology of the soleus and extensor digitorum longus muscles. Neurol. Sci. 80: 39-54.

Cossu, G. and M. Molinaro. 1987. Cell heterogeneity in the myogenic lineage. Curr. Top. Dev. Biol. 23: 185-208.

Coulton, G.R., J.E. Morgan, T.A. Partridge, and I.C. Sloper. 1988. The mdx mouse skeletal muscle myopathy: I. A histochemical, morphometric, and biochemical investigation. Neuropathol. Applic. Neurobiol. 14: 53-70.

Fuchtbauer, E.-M. and H. Westphal. 1992. MyoD and myogenin are coexpressed in regenerating skeletal muscle of the mouse. Dev. Dynam. 193: 34-39.

Gavrieli, Y., Y. Sherman, and S.A. Ben-Sasson. 1992. Identification of programmed cell death in situ via specifiC labeling of nuclear DNA fragmentation. I. Cell Biol. 119: 493-501.

George-Weinstein, M., R.F. Foster, J.V. Gerhart, and S.J. Kaufman. 1993. In vitro and in vivo expression of $\alpha 7$ integrin and desmin define primary and secondary myogenic lineages. Dev. Biol. 156: 209-229.

Goldhamer, D.J., A. Faerman, M. Shani, and C.P. Emerson. 1992. Regulatory elements that control the lineage specific expression of MyoD. Science 256: 538-541.

Goldhamer, D.J., B.P. Brunk, A. Faerman, A. King, M. Shani, and C.P. Emerson. 1995. Embryonic activation of the myoD gene is regulated by a highly conserved distal control element. Development 121: 637-649.

Grounds, M.D. 1991. Towards understanding skeletal muscle regeneration. Pathol. Res. Pract. 118: 1-22.

Grounds, M.D. and Z. Yablonka-Reuvini. 1993. Molecular and cellular biology of muscle regeneration. In Molecular and cellular biology of muscular dystrophy (ed. T. Partridge), pp. 210-256. Chapman and Hall, London, UK.

Hasty, P., A. Bradley, J.H. Morris, D.G. Edmondson, J. Venuti, E.N. Olson, and W.H. Klein. 1993. Muscle deficiency and neonatal death in mice with targeted mutation in the myogenin gene. Nature 364: 501-506.

Hauschka, S.D. 1994. The embryonic origin of muscle. In $M y$ ology 2nd ed. (ed. A.G. Engel and C. Franzini-Armstrong), pp. 3-73. McGraw-Hill, New York, NY.

Johnson, S.E. and R.E. Allen. 1993. Proliferating cell nuclear antigen (PCNA) is expressed in activated skeletal muscle satellite cells. J. Cell. Physiol. 154: 39-43.

Kablar, B. 1995. Structural study on the appearance of innervation in the stomach of mouse and rat embryos. Tiss. Cell 27: 309-315.

McGeachie, J.K. and M.D. Grounds. 1990. Applications of an autoradiographic model of skeletal muscle myogenesis in vivo. In Pathogenesis and therapy of Duchenne and Becker muscular dystrophy (ed. B.A. Kakukas and F.L. Mastaglia), pp. 151-170. Raven Press, NY.

Megeney, L.A. and M.A. Rudnicki. 1995. Determination versus differentiation and the MyoD family of transcription factors. Biochem. Cell. Biol. 73: 723-732.

Miller, J.B. 1992. Myoblast diversity in skeletal myogenesis: How much and to what end? Cell 69: 1-3.

Mitchell, C.A., J.K. McGeachie, and M.D. Grounds. 1992. Cellular differences in the regeneration of murine skeletal muscle: A quantitative histological study in SJL/J and BALB/C mice. Cell Tissue Res. 269: 159-166.

Nabeshima, Y., K. Hanaoka, M. Hayasaka, E. Esumi, S. Li, I. Nonaka, and Y. Nabeshima. 1993. Myogenin gene disruption results in perinatal lethality because of severe muscle defect. Nature 364: 532-535.

Olson, E.N. 1992. Interplay between proliferation and differentiation within the myogenic lineage. Dev. Biol. 154: 261272.

Ontell, M.P., D. Hughes, S.D. Hauschka, and M. Ontell. 1992.
Transient neonatal denervation alters the proliferative capacity of myosatellite cells in dystrophic $\left(129 \mathrm{ReJ}^{\mathrm{dy} / \mathrm{dy}}\right)$ muscle. I. Neurobiol. 23: 407-419.

Patapoutian, A., J.K. Yoon, J.H. Miner, S. Wang, K. Stark, and B. Wold. 1995. Disruption of the mouse MRF4 gene identifies multiple waves of myogenesis in the myotome. Develop. ment 121: 3347-3358.

Rando, T.A. and H.M. Blau. 1994. Primary mouse myoblast purification, characterization, and transplantation for cell-mediated gene therapy. I. Cell Biol. 125: 1275-1287.

Rudnicki, M.A. and R. Jaenisch. 1995. The MyoD family of transcription factors and skeletal myogenesis. BioEssays 17: 203-209.

Rudnicki, M.A., T. Braun, S. Hinuma, and R. Jaenisch. 1992. Inactivation of $\mathrm{MyoD}$ in mice leads to upregulation of the myogenic HLH gene Myf5 and results in apparently normal muscle development. Cell 71: 383-390.

Rudnicki, M.A., P.N.J. Schnegelsberg, R.H. Stead, T. Braun, H.H. Arnold, and R. Jaenisch. 1993. MyoD or Myf-5 is required for the formation of skeletal muscle. Cell 75: 13511359.

Schultz, E. 1976. Fine structure of satellite cells in growing skeletal muscle. Am. J. Anat. 147: 49-60.

Sicinski, P., Y. Geng, A.S. Ryder-Cook, E.A. Barnard, M.G. Darlison, and P.J. Barnard. 1989. The molecular basis of muscular dystrophy in the $\mathrm{mdx}$ mouse: A point mutation. Science 244: 1578-1580.

Smith, C.K., M.J. Janney, and R.E. Allen. 1994. Temporal expression of myogenic regulatory genes during activation, proliferation, and differentiation of rat skeletal muscle satellite cells. I. Cell. Physiol. 159: 379-385.

Stedman, H.H., H.L. Sweeney, J.B. Shrager, H.C. Maguire, R.A. Panettieri, B. Petrof, M. Narusawa, J.M. Leferovitch, J.T. Sladky, and A.M. Kelly. 1991. The mdx mouse diaphragm reproduces the degenerative changes of Duchenne muscular dystrophy. Nature 352: 536-539.

Stockdale, F.E. 1992. myogenic cell lineages. Dev. Biol. 154: 284-298

Tapscott, S.J., A.B. Lassar, and H. Weintraub. 1992. A novel myoblast enhancer element mediates MyoD transcription. Mol. Cell. Biol. 12: 4994-5003.

Venuti, J.M., J. Hsi-Morris, J.L. Vivian, E.N. Olson, and W.H. Klein. 1995. Myogenin is required for late but not early aspects of myogenesis during mouse development. J. Cell Biol. 128: 563-576.

Webster, C. and H.M. Blau. 1990. Accelerated age-related decline in replicative life-span of Duchenne muscular dystrophy myoblasts: Implications for cell and gene therapy. Somatic. Cell Mol. Genet. 16: 557-565.

Weintraub, H., R. Davis, S. Tapscott, M. Thayer, M. Krause, B. Benezra, T.K. Blackwell, D. Turner, R. Rupp, S. Hollenberg, Y. Zhuang, and A.B. Lasser. 1991. The myoD gene family: Nodal point during specification of the muscle cell lineage. Science 251: 761-766.

Yablonka-Reuveni, Z. and A.J. Rivera. 1994. Temporal expression of regulatory and structural muscle proteins during myogenesis of satellite cells on isolated adult rat fibers. Dev. Biol. 164: 588-603.

Zhang, W., R.R. Behringer, and E.N. Olson. 1995. Inactivation of the myogenic bHLH gene MRF4 results in upregulation of myogenin and rib anomalies. Genes \& Dev. 9: 1388-1399. 


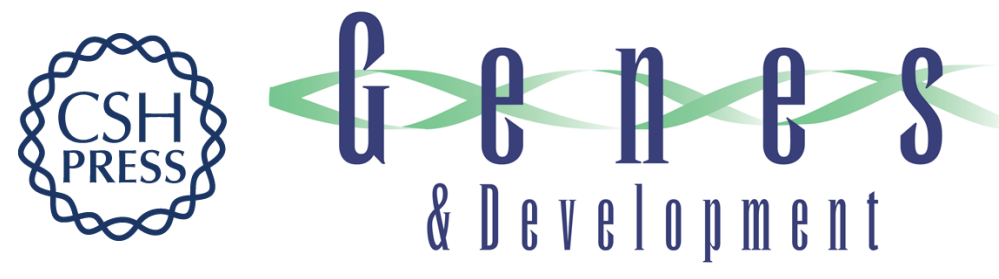

\section{MyoD is required for myogenic stem cell function in adult skeletal muscle.}

L A Megeney, B Kablar, K Garrett, et al.

Genes Dev. 1996, 10:

Access the most recent version at doi:10.1101/gad.10.10.1173

References This article cites 42 articles, 12 of which can be accessed free at:

http://genesdev.cshlp.org/content/10/10/1173.full.html\#ref-list-1

License

Email Alerting

Service

Receive free email alerts when new articles cite this article - sign up in the box at the top right corner of the article or click here.

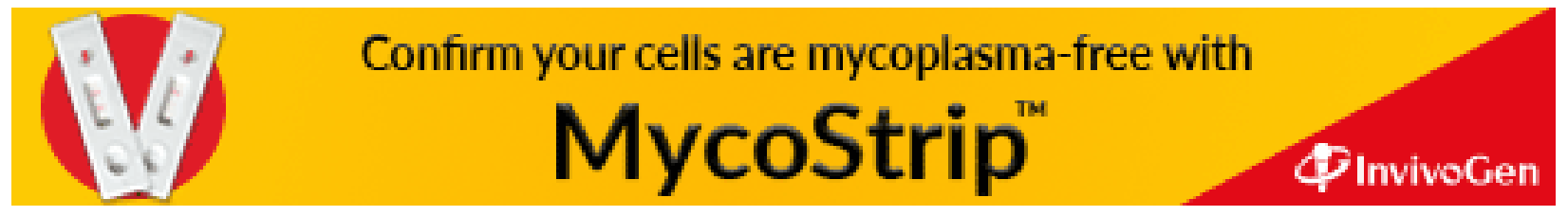

